\title{
La in-validez del cuerpo de la letrada: la metáfora patológica
}

The Dis-Ability of the Learned Woman's Body: the Pathological Metaphor A in-validade do corpo da letrada: a metáfora patológica

\section{Beatriz González-Stephan}

RICE UNIVERSITY

Profesora del Departamento de Estudios Hispánicos en Rice University.

PhD en Literatura Hispanoamericana por Pittsburgh University.

Autora de Fundaciones: canon, historia y cultura nacional (Vervuert

/ Iberoamericana, 2002); La historiografía literaria del liberalismo

hispanoamericano del siglo XIX (Casa de las Américas, 1987); y editora

de Galerías del progreso: museos, exposiciones y cultura visual en

América Latina (Beatriz Viterbo, 2006), Nación y literatura: itinerarios

de la palabra en la cultura venezolana (Fundación Polar, 2006),

Esplendores y miserias del siglo XIX. Cultura y sociedad en América

Latina (Monte Ávila, 1995). Correo electrónico: beatriz@rice.edu

Artículo de reflexión

Este ensayo es una versión corregida de "La invalidez del cuerpo de la letrada: la metáfora patológica", en Revista Iberoamericana No. 210, enero-marzo 2005, 55-75. 


\section{Resumen}

El trabajo hace un análisis de la breve novela Dolores (1869) de la escritora colombiana Soledad Acosta de Samper, que desarrolló a lo largo de su no corta vida una extensa e intensa actividad intelectual. En este texto se problematiza la relación implícita que hay entre la mujer como sujeto intelectual y su cuerpo enfermo como alegorización de una subjetividad incómoda para la comunidad letrada masculina, que reconvierte esa disonancia en metáfora del cuerpo patológico (en este caso, un cuerpo leproso que se desintegra monstruosamente) como sinónimo de mujer letrada. También, por tanto, la escritura de ese cuerpo enfermo puede contagiar a otros a través de la escritura de unas letras fuera del canon; de aquí el género epistolar, íntimo, que contagia la integridad genérica de la república de las letras.

Palabras clave: Soledad Acosta de Samper, Dolores, género epistolar, narrativas médicas, contagio.

Palabras descriptor: Soledad Acosta de Samper, Dolores - Crítica e interpretación, novela colombiana, literatura colombiana, medicina narrativa.

\section{Abstract}

The present paper analyses Dolores (1869), a short novel by Colombian writer Soledad Acosta de Samper, who undertook intense and extensive intellectual activity during her prolonged lifetime. This paper discusses the implicit relationship between the woman as an intellectual subject and her ill body as the allegory of a type of subjectivity uncomfortable for the community of learned men, through which such dissonance is retransformed into a metaphor of the pathological body (in this case, a leprous body that disintegrates in a monstrous way) as a synonym of the learned woman. In this way the writing of such a body can also infect others through a style of writing which transgresses the cannon; thus the epistolary genre, intimate, infecting the generic integrity of the republic of literature.

Keywords: Soledad Acosta de Samper, Dolores, Epistolary Genre, Medical Narratives, Infection.

Keywords plus: Soledad Acosta de Samper, Dolores - Criticism and interpretation, Colombian novel, Colombian literature, narrative medicine.

\section{Resumo}

O trabalho faz análise do breve romance Dolores (1869) da escritora colombiana Soledad Acosta de Samper, que desenvolveu ao longo da sua não curta vida uma extensa e intensa atividade intelectual. Este texto problematiza a relação implícita entre a mulher como sujeito intelectual e seu corpo doente como alegorização de uma subjetividade incômoda para a comunidade letrada masculina, que reconverte essa dissonância em metáfora do corpo patológico (neste caso, um corpo leproso que desintegra-se monstruosamente) como sinônimo da mulher letrada. Também, por tanto, a escrita desse corpo doente pode contagiar aos outros através da escrita de umas letras fora do cânon; daqui o gênero epistolar, íntimo, que contagia a integridade genérica da república das letras.

Palavras-chave: Soledad Acosta de Samper, Dores, gênero epistolar, narrativas médicas, contágio.

Palavras-chave descritores:

Soledad Acosta de Samper, Dolores - crítica e interpretação, romance colombiano, literatura colombiana, medicina narrativa. 
"The monster woman is the woman who refuses to be selfless, acts on her own initiative, who has a story to tell -in short-, a woman who rejects the submissive role patriarchy has reserved for her".

TORIL MOI

"Sois bastante bella; sois muy inteligente. Vos lo sabéis; pero creedme, desearía que os pagáseis más de vuestra hermosura que de vuestro talento. Entre Venus y Doña Emilia Pardo Bazán los hombres preferimos a Venus". RUFINO BLANCO FOMBONA

ME SORPRENDE QUE, en medio de su prolífica e intensa vida intelectual, Soledad Acosta de Samper (Colombia, 1833-1913) haya destinado una constancia inquebrantable para dirigir durante más de cincuenta años la Revista de San Lázaro con el objeto de recaudar fondos para la colonia de leprosos Agua de Dios. ¿Caridad cristiana? ¿Compromisos familiares? Sin duda. Pero las figuras leprosas, las imágenes de su deformación monstruosa, recorren sus tempranas narraciones... entre ellas, el texto que más ha llamado el interés de la crítica contemporánea, Dolores (cuadros de la vida de una mujer) (1869), amén de haber sido el más reeditado y traducido al inglés en vida de la autora'. Sin embargo, sería ingenuo, además de subestimar la inteligencia perspicaz y la vasta cultura literaria de Soledad Acosta, hacer una proyección biográfica para explicar la engañosa simplicidad de Dolores. El cuadro leproso de la enfermedad de la protagonista, Dolores, se inscribe en el tejido de una tradición literaria y médica con la cual dialoga y

$1 \quad$ Dolores se publicó por primera vez como folletín en El Mensajero en 1867, bajo el seudónimo de Aldebarán. Luego fue recogido junto con otros textos en forma de libro en Novelas y cuadros de la vida sur-americana, publicado en Gante (Imprenta de Eug. Vanderhaeghen, 1869, 438 páginas), con un prólogo de José María Samper; fue traducido posteriormente al inglés bajo el título de Dolores: The Story of a Leper (Nueva York). Las narraciones que configuran el libro circularon primero como folletines en varios periódicos y también bajo algunos seudónimos que Soledad Acosta usaba para encubrir su persona. "Teresa la limeña. Páginas de la vida de una peruana" (folletín en La Prensa, 1868, Aldebarán); "El corazón de la mujer (ensayos psicológicos)" (folletín en El Hogar, 1868-1869, Aldebarán); "La Perla del Valle" (El Mosaico, 1864, Andina); "Ilusión y realidad" (El Iris, 1866, Aldebarán); "Luz y sombra (cuadros de la vida de una coqueta)" (El Iris, 1866, Aldebarán) son algunos de los relatos que fueron leídos antes de su formato en libro y bajo la máscara de una falsa identidad autorial. Es interesante destacar que cuando su esposo prologó el libro y respaldó públicamente la gestión literaria de Soledad Acosta se develó la verdadera identidad detrás de los seudónimos. Aparte del gusto detectivesco por resolver acertijos identitarios, en este caso "protegían" el nombre de la hija del historiador y diplomático General Joaquín Acosta. En el presente trabajo todas las citas de Dolores se harán de la edición preparada por Montserrat Ordóñez, Soledad Acosta de Samper. Una nueva lectura. 
discute ajustando sus tropos y figuras. Nada más lejano, entonces, que un relato de la enfermedad como tal. Y en este punto quiero traer a colación las primeras líneas del conocido libro de Susan Sontag en el que enfatiza que su tema no "es la enfermedad física en sí, sino el uso que de ella se hace como figura o metáfora" (9): "la enfermedad no es una metáfora" aclara, pero las enfermedades circulan en el discurso de una cultura cargadas de un lenguaje que las califica moral y socialmente. Lo que interesa, en este caso, es la carga políticamente sexuada en el uso de la enfermedad como metáfora, como tropo literario, particularmente en la esfera del poder letrado en plena configuración de las letras nacionales a mediados del siglo XIX; poder de las letras en manos de un cenáculo masculino que difícilmente las compartía democráticamente.

Tengo varios años retornando a la lectura de Dolores y siempre encuentro detalles aparentemente inadvertidos cuyo reparo despiertan nuevas preguntas. Quizás la más evidente y la más señalada, pero no lo suficiente, sea la contigüidad entre la enfermedad y la mujer intelectual, entre la lepra y la sexualización del saber; en otras palabras: ¿qué ciudadanías aparecen en el reparto de las representaciones imaginarias como necesariamente patológicas e inváli(da) das? La diseminación y el funcionamiento de las narrativas del contagio, y específicamente el poder de la ficción como agente "infeccioso", y no las enfermedades como fuente de contaminación, sino el peligro de contagio de las letras: es decir, ¿en qué medida qué tipo de literatura contamina y subvierte no solo las subjetividades femeninas sino también las masculinas? El relato enmarcado (la voz de Pedro que presenta la narración de Dolores) en ese juego de voces sexualmente travestidas que también excede y prolifera en los márgenes del texto de Dolores (José María Samper, el esposo, autoriza en el prólogo el libro Novelas y cuadros de la vida sur-americana de Soledad Acosta de Samper; Soledad Acosta habla por la figura de Pedro; Pedro por Dolores, y Dolores por Soledad Acosta); ¿qué ansiedades subyacen en esa inestabilidad identitaria? ${ }_{\mathrm{C}}$ Por qué el enmascaramiento del género sexuado en la atribución de la autoridad discursiva? Finalmente, ¿se trata de un texto que habla sobre la insanidad de ciertas ciudadanías o sobre el trauma y los riesgos que representa la configuración de la autoría femenina en un mundo controlado por voces y géneros masculinos? Ambas. Dolores es una puesta en escena, una representación (una escenificación) de un tramado de prácticas discursivas que tienen como centro el miedo a la autoridad de la voz de la mujer; también es una re-presentación en el sentido de re-producir para visualizar mejor las obturaciones y zonas oscuras (deformantes) de la cultura (literaria y médica) patriarcal. Es un texto reflexivo que interroga las tachaduras y los secretos que el cuerpo letrado oculta para prohibir el lugar de enuncia- 
ción de un sujeto no masculino; revisa los modelos retóricos de las estéticas recibidas; conspira desde y contra las representaciones construidas para las mujeres que no guardaban silencio.

\section{Cartas contagiosas}

Dolores está estructurada en tres partes. La historia de la protagonista -que básicamente consiste en la relación de su infortunio al contraer la lepra y tener por tanto que retraerse de la sociedad, sacrificar su noviazgo y futuro matrimonio, y vivir aislada- es narrada por su primo Pedro, con quien Dolores mantiene durante años una comunicación epistolar, a través de la cual le va notificando los avances de la enfermedad y su estado anímico, pero también comparte sus lecturas y escritos. Pedro, una vez fallecida su prima, revela el secreto de su historia al mostrar fragmentos de las cartas y el diario de la difunta. Así, el cuadro de la vida de Dolores es presentado a dos voces y también en dos estilos narrativos que se van alternando: primero, es la voz de Pedro, que en su his-story introduce a los personajes, los paisajes, las costumbres del lugar, las fiestas populares, los idilios (el suyo con Mercedes, luego el de Mercedes con Basilio, el de Dolores con Antonio, y finalmente el de Antonio con "una señorita de las mejores familias de la capital" [80]), como también los no pocos años de la vida de su prima como leprosa. Tanto Pedro como su padre tienen la mirada clínica (son ambos médicos) para leer los síntomas sospechosos de la enfermedad de Dolores desde el principio. Y, segundo, la her-story de Dolores, que se va abriendo paso en el relato de Pedro, hasta terminar por ocupar toda la escena narrativa y desplazarlo a él; es más, Pedro es quien va cediendo su espacio -solo es el marco- para que sea la voz de ella quien performe su propia relación en la medida en que se agrava la enfermedad y su aislamiento se radicaliza. A diferencia de la narración de Pedro, las cartas y el diario de Dolores no se detienen en detalles del mundo exterior, en la historia de otros, sino que el centro lo ocupa el acontecer de su propia persona, las circunstancias límites en las que se desenvuelve la "vida de una mujer", como bien reza el subtítulo del texto. En este sentido, Dolores se inscribe en el proyecto narrativo de los ensayos psicológicos tan caros para Soledad Acosta en aquellos años de su trayectoria intelectual, más inclinada a explorar las situaciones de mujeres solas que a desarrollar el melodrama de la familia sentimental².

2 Soledad Acosta, desde sus tempranas incursiones en la narrativa, como sus Novelas y cuadros de la vida sur-americana, que reunía una serie de cuadros que estudiaban tipologías femeninas que ahondaban más bien en situaciones no necesariamente vinculadas al idilio, hallaría continuidad en su obra posterior, como su voluminoso trabajo de más de cuatrocientas páginas, $L a$ mujer en la sociedad moderna. Se podría considerar este libro como uno de los más sorpren- 
Los síntomas que vaticinan la aparición de la terrible enfermedad ("Un temor vago me asaltó, como a mi padre, al notar el particular colorido de su tez" [46]), la atmósfera de fatales presagios ("el filósofo búho [...] se quejaba con su grito de mal agüero" [29]), y los estragos que causan en la vida de Dolores sin duda captan el interés de cualquier lectura, incluso la de la crítica literaria. Si la protagonista hubiera muerto tísica o clorótica no habría llamado tanto la atención (es lo más frecuente entre las narrativas del XIX) como esta enfermedad que arremete contra las identidades corporales de sus pacientes transformándolos en monstruosidades desfiguradas. Pero, ¿ ¿cuál es la verdadera fuente del horror? ${ }_{\mathrm{i}}^{\mathrm{L}} \mathrm{a}$ etiología de la enfermedad? ¿La gramática del contagio?

Quiero detenerme en un detalle y leer todo el texto en reverso a partir de él, arriesgándome a resemantizar los sentidos de los demás elementos. Dolores, aún joven y saludable, recibe un día en sus manos una carta dirigida a su tía -con la cual vivía desde que se había quedado huérfana-, cuyo remitente debía ser celosamente guardado en secreto, dado que se trataba del padre leproso de Dolores, que había querido "desaparecer" para no contagiar a su hija. El padre, sin embargo, desde su confinamiento, mantiene una asidua y clandestina correspondencia con su hermana. Dolores, efectivamente, crece creyendo en su orfandad. Pero ese día Dolores toma la carta, y cuando se dispone a dársela a su tía, el mensajero le grita: "Tira esa carta, Dolores, ¡tírala! [...]. Mi tía hizo entonces que me lavara las manos, y mandando llevar un brasero, no tomó la carta en sus manos sino después de haberla hecho fumigar" (48; el énfasis es mío). Dolores queda tan sorprendida con esta reacción que apenas atina a preguntar si:

¿Está envenenado ese papel, tía? El viejo Simón tendrá sus rasgos a lo Borgia, como en la historia que leíamos el otro día?

-No te burles, hija mía, me contestó [la tía] con seriedad: el veneno que puede contener ese papel es más horrible que todos los que han inventado los hombres $[\ldots]$.

-Es preciso que me explique usted este misterio...

dentes esfuerzos por parte de una mujer latinoamericana en el XIX por hacer una historia de las mujeres intelectuales, letradas, artistas, músicas, compositoras, políticas, médicas, economistas, astrónomas, matemáticas de Europa, Estados Unidos, América Latina y el Caribe. En este sentido, creo que Soledad Acosta no abandonó sus preocupaciones iniciales. Lo que sí modificó fue el género literario: pasó de la ficción al ensayo, pero mantuvo la estrategia "biográfica", es decir, una narrativa que individuase la subjetividad de la mujer. También rastreó con ejemplos concretos tomados de la historia la posibilidad "real" de desempeño de la mujer fuera del matrimonio. Las biografías que integra esta obra debían servir como cuadros modélicos para la self-help de la mujer latinoamericana. 
$-{ }_{\mathrm{i}}$ No sabes que en las inmediaciones de $\mathrm{N}^{* * *}$ hay lazarinos? Uno de esos desgraciados me ha enviado esa carta [...]. Se dice que esa espantosa enfermedad se comunica con la mayor facilidad [...].

-Mucho me ha interesado [Dolores]: el sobrescrito de la carta estaba muy bien puesto... y aún me parece que la letra no me es enteramente desconocida. (48-49, el énfasis es mío)

La enfermedad que se contagia a través de la carta no es la lepra, es decir, la lepra como Patología; el veneno que se desprende de la carta ("el papel envenenado") es la escritura, la escritura que envenena. El contagio se deriva de producir y descifrar la letra; es el contagio que produce la literatura en general ("se comunica con la mayor facilidad"), y particularmente los géneros íntimos como formas de ficción altamente contagiosas ("el veneno que puede contener ese papel es más horrible que todos los que han inventado los hombres"). Las narrativas que descansan en el mundo de la privacidad (las narrativas del yo), que construyen una subjetividad que intensifica una mayor sensibilización, resultan a la postre más tóxicas, menos edificantes, más peligrosas que los géneros didáctico, histórico o religioso. Ese sería uno de los ángulos de la "fumigación", amén de la capacidad perturbadora que ya trae el "vicio" de la lectura al (des) orientar la educación de la mujer e indisciplinar su domesticidad. La literatura de ficción -el papel, la carta- se vuelve un instrumento temible ("a lo Borgia") si cae en manos inapropiadas, como en las manos de las mujeres porque las incitaría (contagiaría) a escribir. Por ello, hay que "fumigar" la letra, evitar y exterminar los gérmenes de su propagación "tirándola al brasero" (49)3. La tía lee la carta, pero no se contamina porque no toca la letra. Por el contrario, la letra sí toca las manos de Dolores y las envenena. Quedará así contagiada ("mucho me ha interesado") por letras que matan, por el poder de la literatura del padre ("la letra no me es enteramente desconocida"):

Había conocido la voz de mi padre [...] y acercándome le eché los brazos al cuello. $\mathrm{Al}$ ver mi acción [...] dieron un grito de horror [...] yo pugnaba por seguirlo [...].

3 El concepto propuesto por Susan Gubar y Sandra Gilbert, infection in the sentence breeds, en el segundo capítulo de su libro The Madwomen in the Attic, "Infection in the Sentence: The Woman Writer and the Anxiety of Authorship" (45-92), es sumamente útil para el punto que estoy tratando en Dolores. Desplaza el centro de atención del discurso del nivel de las representaciones al plano de los géneros literarios propiamente dichos. Y es en este sentido que la literatura como praxis social (su consumo) invade, contagia y modela las subjetividades. La "fiebre" que produce es una metáfora que apunta a su capacidad de agenciamiento e interpelación. 
-Dolores, no te acerques, ;por Dios!... ¡ está lazarino!

- ¿Lazarino? ¡qué me importa! Mi padre no ha muerto y quiero abrazarlo. (51, el énfasis es mío)

Hereda ("abraza") del padre la lepra como metáfora del poder metafórico de las letras: en cierto modo se trata para ella del don fatal de producir letras: versos, prosas, y también cartas ${ }^{4}$.

La literatura es tan contagiosa (tocar la carta) como la lepra (hay que lavarse las manos); la ley de su propagación re-produce los mismos síntomas y patologías. Abraza y sigue la voz del padre: hereda, al abrazarlo, el designio de tener también una voz para poder hablar. Así, en la medida en que la lepra consume el cuerpo de Dolores, ella produce en una relación inversamente proporcional un cuerpo textual sustitutivo. Ahora es su voz la que lucha por manifestarse. Se encuerpa en el don letrado que le dejó su padre. Se re-configura y re-genera -la propagación es la ley del contagio- en la escritura de cartas, diarios, versos, ensayos, traducciones... Del mismo modo que la carta del padre la contagia, y en cierto modo la "masculiniza", porque recibe la tradición literaria del padre que la pervierte a favor de las letras en detrimento del matrimonio, ella a su vez con su escritura también contagia a Pedro: en cierto modo él se "feminiza" por la lectura de los escritos de Dolores; termina por no casarse con Mercedes y opta por un destino tan solitario como el de su prima. Ninguno de los dos -como veremos más adelante- se inserta en las narrativas del idilio reproductivo. La neuromímesis que producen ciertas narrativas (Bailin, Beizer, Gilman, Kahane, Nouzeilles, Silva, Vicinus, Vrettos) contagia subjetividades excesivas -dis-funcionales o patológicas-, porque logra transmitir -como las enfermedades- conductas desviadas del orden: “... ¡Dios, la religión, la vida futura! ¡Cuestiones insondables! ¡Terribles vacilaciones de mi alma! ¡Si mi mal fuera solamente físico, si tuviera solamente enfermo el cuerpo!"” (84, el énfasis es mío).

4 Aunque Soledad Acosta no se está "autobiografiando" en esta novela -como tampoco en ninguna otra de su cosecha-, sí inscribe en sus textos de ficción su propio horizonte experiencial como una mujer de los sectores acomodados de la sociedad bogotana que ha tenido el privilegio de crecer y circular en el mundo intelectual tanto de Colombia como de Europa. Es interesante señalar cómo también Soledad Acosta hereda de su padre, Joaquín Acosta, no solo el gusto por el saber, las letras, la biblioteca, los viajes, sino una red de amistades intelectuales, entre las cuales va a crecer y desarrollar una intensa correspondencia, vínculos que le permitirán ejercer "naturalmente" las letras y desempeñarse como escritora, periodista, conferenciante, traductora, maestra, y luego individuo de la Real Academia de la Historia. Dolores es una sofisticada y simbólica puesta en escena de esta herencia. 


\section{La ansiedad autorial}

Dolores queda contagiada con la autoridad letrada del padre; recibe de él la pasión patológica por la letra. Por consiguiente, la herencia literaria que la abraza -porque es la única letra paterna que recibe- le viene dada por un padre literario y no por una madre literaria. Su temprana vocación por las letras solo encuentra a mano modelos -libros, historias, relatos, ensayos, novelas, cartas...de la tradición literaria masculina. La única voz que abraza es la del padre; es la única que tiene disponible ("mi padre no ha muerto") en forma de una tradición objetivada en libros que le permite leer, ejercitarse, citar, imitar:

A veces me propongo estudiar, leer, aprender para hacer algo, dedicarme al trabajo intelectual y olvidar así mi situación: procuro huir de mí misma, pero siempre, siempre el pensamiento me persigue, y como dice un autor francés: 'Le chagrín monte en croupe et galope avec moi'. (85, el énfasis es mío)

No tiene otra opción: la tradición de letras femeninas aún no se ha construido, se ha silenciado; solo puede inscribirse en el canon letrado patrilineal, en la biblioteca del padre, y en los libros que permanentemente le suministra Pedro. No solo la carta del padre es uno de los emblemas más significativos, sino todo el sistema de referencias que maneja Dolores que, como el de Soledad Acosta, pasa por el canon "autorizado". Epígrafes de autoridades literarias europeas -Víctor Hugo, Balzac, Gilbert- encabezan las tres secciones de la novela. Es la biblioteca que la escritora hereda del padre,Joaquín Acosta, y del esposo,José María Samper.

Pero, dentro del registro de géneros literarios marcados por el sujeto masculino, la voz del padre que la contamina con la misma "lepra", ¿cómo separarse del padre? ¿Cómo, entonces, marcar la diferencia? ¿Cómo elaborar una letra que difiera de la tradición del padre? ¿Cómo generar letras ante la ausencia de paradigmas que puedan vocear las subjetividades femeninas? ¿Dónde abrevar de otra tradición literaria que no la señale como raro espécimen?: "Siempre el silencio, la soledad, la ausencia de una voz amiga que me acaricie con un tono de simpatía" (84, el énfasis es mío). Evidentemente, la escena del saber y de la producción literaria está tomada por el cuerpo masculino, y el no lugar para otras voces produce ese desierto de soledad y ansiedad:

¿Para quién aprendo yo? Mis estudios, mi instrucción, mi talento, si acaso fuera cierto que lo tuviera, todo esto es inútil, pues jamás podré inspirar un sentimiento de admiración: estoy sola, sola para siempre... Vegeto como un árbol carcomido: vivo como una roca en un lugar desierto... (85) 
La ausencia de figuras y tropos literarios de una tradición matrilineal produce al tiempo una parálisis ("todo es inútil") y una ansiedad ("¿para quién aprendo yo?") por conseguir un lugar en la audiencia literaria ("jamás podré inspirar un sentimiento de admiración"). Marcar una voz diferencial, "pugnar" por el desvío del canon ("procuro huir de mí misma"), pasan a convertirse en el proyecto existencial de Dolores; de otro modo, el proyecto estético-literario de Soledad Acosta con Dolores es llevar a la escena textual la lucha (la "pugna") por estabilizar políticamente la autoridad y legitimidad de la mujer letrada, y su derecho a fundar sus propios tropos literarios sin que sean des-figurados (por la lepra) por la voz del padre y sin tener que enmascarar su identidad literaria:

- ¿Qué es esto prima?

-Estaba escribiendo y...

${ }_{-}^{-} \mathrm{i} Y$ esa carta?

-iNo es carta!

-Misiva, pues, dije riéndome, epístola, billete, como quieras llamarla.

-Toma el papel; haces que te muestre lo que solo escribía para mí.

Y me presentó un papel en que acababa de escribir unos preciosos versos, que mostraban un profundo sentimiento poético y cierto espíritu de melancolía vaga que no le conocía. (45-46, el énfasis es mío)

Su lucha por el poder interpretativo de la palabra implicará, como toda pugna, un duelo, un esfuerzo doloroso de afrentas y renuncias. El precio del gesto de la diferencia es alto: ella ensaya versos, prosas, cartas, diarios ("misiva, epístola, billete, como quieras llamarla") en un intento por darle otra forma a su identidad literaria y poder abrirse un espacio reconocible dentro de las narrativas patriarcales.

\section{El desvío dif(i)erencial}

La palabra difierencial es la que construye en la escritura una nueva subjetividad distanciada del padre (Derrida, "La différence"; La escritura y la diferencia). Pero esa construcción de momento está atravesada por inestabilidades de género (¿la narración es de él o de ella?, ¿o ella narra a través de él?), y un experimentalismo que ensaya sus formas, "huyendo" de la voz del padre que "siempre la persigue", hasta poder encontrar sus propias formas expresivas, su propio lenguaje. Por eso, Pedro solo puede mostrar partes de las cartas de Dolores, fragmentos de su diario, pero no sus versos y otras prosas. También de momento "solo escribe para ella" dentro de la estricta privacidad del claustro. Pero incursionar en la difierencia es quedar otra vez atrapada en las cárceles del lenguaje, 
que no solo la desnaturalizan como ciudadana (mujer y leprosa), sino que para nombrarse ("como quieras llamarla") solo tiene el lenguaje del padre.

Al ser el verbo en su principio vital masculino, el ella epistemológicamente no tiene lugar. Dentro del lenguaje del padre ella es estructuralmente anónima (Derrida, El monolingüismo). Para nombrarse solo tiene las categorías del otro masculino (del sujeto médico) que la diagnostica des-figurada en una doble interdicción: sin identidad y sin habla, porque la lepra se "carcomerá" su cuerpo y su lengua. Su lucha no es contra la enfermedad, sino contra esta des-identidad originaria que la amordaza desde su confinamiento. Su escritura en fragmentos, fragmentada, es el gesto inconcluso de la supresión que regresa a la escena para cobrar "como una fiera de los bosques" (70) lo que el padre le ha robado. La "invalidez" que produce la carencia de un lenguaje propio para expresarse la llevan a estados de "locura y desesperación" (70). Las "prótesis" verbales del padre o la biblioteca de Pedro no sustituyen su lenguaje. Dolores, como escritora, está por tanto des-valida de su propio cuerpo literario, porque las letras siempre han sido ejercidas por una "pen/penis" (Gubar y Gilber).

Para ella, apropiarse de la letra es un infortunio, porque la patología de la lepra contamina sexuadamente los cuerpos. La lepra/letra en manos de la mujer desvía el sentido establecido; el género sexuado contaminado marca el sentido de la diferencia. Es la voz de la mujer que habla, piensa y escribe la disonancia en el registro de los saberes masculinos:

Una noche había leído hasta muy tarde, estudiando francés en los libros que me dejaste: procuraba aprender y adelantar en mis estudios, educar mi espíritu e instruirme para ser menos ignorante: el roce con algunas personas de la capital me había hecho comprender últimamente cuán indispensable es saber. (50)

Por eso Dolores produce repugnancia y horror. Esa apropiación es impropia ("estudiando francés en los libros que me dejaste"), distorsiona el cuerpo de las letras, y carcome el tronco de la tradición, porque es ella quien contaminará a la postre el canon letrado con $s u$ letra, aunque sea con una imperceptible inflexión. Dolores marca en cursivas el discurso alterando la gramática de su contagio: el roce con "algunas personas" la hace comprender la importancia del saber letrado para las mujeres. Aquí la diferencia se vuelve patológica; debe ser patologizada por las narrativas médicas (Pedro y su padre son los médicos que diagnostican la anormalidad de la tez de Dolores) para poder aislarla y evitar futuras propagaciones entre el género de su especie (no en vano Dolores solo se comunica con Pedro; es sometida a un contacto controlado). 
La lepra es, entonces, la marca de una diferencia patológica, la que corresponde a la mujer intelectual, peligrosa, porque ha subvertido la paternidad del saber de las letras. La desfiguración parece venirle de los "muchos libros sobre las mesas" (75). El discurso va aparejando los libros, la escritura, con la deformación física creciente. No solo debe ser aislada, encerrada, sino desfigurada hasta la monstruosidad, porque además ha alterado el orden de adscripción de los roles sexuados. La ética del poder falocrático la penaliza con su fealdad. Su afición por los libros y el saber la llevan a no contraer matrimonio ("ella dice que jamás se casará"; "no quiero creer en la repugnancia de Dolores por el matrimonio" [63]); no le interesa la maternidad; decide vivir sola lejos de lazos familiares; y como escritora, intenta re-escribir las representaciones y modelos retóricos hegemónicos, amén de cuestionar el orden de creencias del discurso religioso: "Otras veces $m i$ alma se rebela, no puede creer en que un Dios bueno me haga sufrir tanto, y en mi rebeldía niego su existencia" (84, el énfasis es mío).

Si bien las narrativas patriarcales y médicas construían para la mujer letrada un cuerpo monstruoso y contaminante que la obligaba al encierro (Price, Russo), este aislamiento podía reconvertirse en una situación productiva (transgresiva, según Stallybrass y White) para la gestación de la voz diferencial. La reclusión de Dolores es necesaria, y no por la lep/tra que padece, sino porque la soledad es condición indispensable para el ejercicio intelectual. Por el contrario, la soledad del hombre letrado se reviste de importancia y distinción. La metáfora de la lepra la desacredita desde el discurso patriarcal; pero al tiempo la exime de ser cuerpo reproductivo, y puede propiciar -en esta interdicción- su pasión letrada. La otra cara de la enfermedad, digamos el lado productivo de la metáfora monstruosa, es que le permite diferir, poder trabajar en su necesaria diferencia.

La monstruosidad patológica de la letrada, que funciona simbólicamente como una supresión de la sociedad patriarcal, incuba desde su denegación la forma de su identidad alterada. Sumergirse en la cueva (Gubar y Gilbert), volver a la gruta, adentrarse en la selva, en la más radical soledad, para no oír las voces dominantes que la puedan contagiar y desviar, alejarse de todos los compromisos sociales (familia, matrimonio, hijos) son también la situación metafórica del cuarto propio para poder ella hallar su propia identidad literaria y poder escuchar su propia voz: "Viviré sola. Mi tía tiene una repugnancia singular al mal que sufro [...]) veo la humanidad entera como un enemigo que me persigue, que me acosa, y he resuelto separarme de todo el que me tema" (69, el énfasis es mío). Dolores, al saberse infectada, abandona a su tía, y con una voluntad firme decide construir su propia casa con su biblioteca en plena selva. Desde allí es ella quien regula sus contactos y comunicaciones ("no se dejaba ver por nadie, y no permitía que se 
le acercasen", 68). La monstruosidad descansa en la mujer que decide vivir sola, que administra su propia hacienda, sin el tutelaje masculino; que evita el matrimonio y que puede desempeñarse como una profesional de las letras.

Dolores en su cueva reescribe el mito de la caverna de Platón, subvirtiendo la semántica patriarcal de la in-validez de la mujer monstruosa. A manera de una olvidada Sibila, inicia el proceso de excavación de una memoria reprimida y (re) construye los fragmentos. El encuevamiento le permite sumergirse en las profundidades de sí misma y encontrar allí, en la pura subjetividad, el poder de una tradición matrilineal diferida. El cuerpo de esa tradición ha sido des-membrado, des-integrado, como su propio cuerpo leproso. Es un cuerpo incompleto, de voces dispersas, de "anomalías" literarias. Entre los epígrafes de la novela, mayormente de escritores, Soledad Acosta halla la voz de Vicenta Maturana. Del mismo modo, en los fragmentos del texto de Dolores, tenemos la escritura interrumpida e inconexa de una subjetividad doliente que ha sido agredida por la violencia patriarcal, y que pugna en un duelo por hacerse, pero también por abrirse paso en un coro que la silencia. La escritura de Dolores escenifica el trauma de la supresión y demonización de la escritora que le han quitado el lenguaje ("estoy loca, desesperada", 66; "mi espíritu es un caos: mi existencia una horrible pesadilla", 79); escenifica el duelo de la des-posesión ("al verme, fue tal el horror que se pintó en sus semblantes, que comprendí que yo no debía hacer parte de la humanidad", 76); al tiempo, inicia el proceso de su (re)composición como individualidad literaria hecha a base de pedazos.

\section{La tradición interrumpida}

Dolores interroga desde la diferencia sexuada de los géneros la escena literaria y la tradición de las narrativas nacionales. El lenguaje de $s u$ diferencia le permite hacer visible el sentido estético-ideológico de los moldes retóricos

5 Soledad Acosta en La mujer en la sociedad moderna (1895) es tajante al respecto: "la vida aislada de una mujer virtuosa, sabia, patriota, etc., no basta para que se comprenda lo que se pide a todas, es preciso presentar un conjunto razonado de biografías, de bocetos de mujeres ejemplares $[\ldots]$ mujeres que han vivido para el trabajo propio, que no han pensado que la única misión de la mujer es la de mujer casada, y han logrado por vías honradas prescindir de la necesidad absoluta del matrimonio [...] le enseñará a valerse por sí misma [...] puede existir sin lazos matrimoniales, y sola, sin necesidad de que un hombre trabaje para darle la subsistencia" (vii, ix). Su lucha como intelectual fue precisamente para des-patologizar la imagen distorsionada que tenía la sociedad de una mujer dedicada a las profesiones. En este sentido, esta obra dialoga entrañablemente con Dolores con relación a hacer visible, por un lado, las dimensiones teratológicas de los prejuicios patriarcales y, por otro, desmentirlos con argumentos historiográficos. 
recibidos, y proceder con cautela en la repetición distanciada del mimetismo acrítico. Es decir, re-producir los modelos de la tradición literaria patriarcal, pero haciendo visibles aquellos mecanismos que hablan por las mujeres, que les mienten, que las domestican, que las castran y anulan. Brevemente, para retomar una idea anterior: hace visible mediante el travestismo la supeditación de la palabra de la mujer a la del hombre (Pedro es la ficción masculina que autoriza la narración de Dolores). Conspira desde y contra las representaciones culturales para insertarse en los intersticios. En este sentido, desteje las narrativas melodramáticas y sentimentales, pone en cuestión la matriz del idilio político (el political romance), y revierte los presupuestos clínicos de las narrativas médicas. Sin llegar a parodiar -en el sentido estricto de burlar- estas estructuras, trabaja la duplicación-parados, canto paralelo- como un gesto, por un lado, de reconocimiento de la tradición hegemónica, y, por otro, de disensión de las restricciones de los sujetos subalternizados. Así pone sobre la escena textual dos voces, la de Pedro y la de Dolores, la voz de Pedro paralela (para) a la de Dolores (dos).

La distribución del relato entre Pedro y Dolores, este juego entre un él y una ella, no solo reproduce los acertijos en torno a la identidad autorial, como señaláramos, sino además entraña implicaciones más complejas en cuanto a la densidad de tramados que esconden las diferencias gramaticales de género. El registro narrativo de Pedro -la voz "masculina" del relato- pone en marcha una concepción política de las letras que desearía garantizar la reproducción de la mujer doméstica y la despolitización del espacio privado en función de la permanencia de la familia burguesa. El eje de su relato solo pareciera adquirir sentido en función de la pareja heterosexual y del idilio reproductivo: la ansiedad de quién se casa con quién, y de cubrir las expectativas de las narrativas sentimentales. Su relato repasa los tópicos trillados del melodrama: el amor a primera vista, la pareja ideal, los malos presagios, el amor fatal, las intrigas, los secretos, el duelo, el abandono, el amor imposible... Dentro de este esquema la mujer es como "las flores arrastradas por la corriente de un río"; y Dolores, una de esas flores que "se precipitan a la corriente y se pierden en un remolino [...] se van hundiendo poco a poco y como a pesar suyo" (42). Las expectativas de este proyecto narrativo fracasan. El idilio feliz no se cumple en ningún caso (ni para Mercedes, ni para Pedro, ni para Antonio, ni para Dolores), y se subraya más bien el carácter libresco de la construcción del amor romántico. Antonio, íntimo amigo de Pedro, en determinada oportunidad exige "ser engañado" pero con "algo verosímil": "yo no soy héroe de novela" (64). Finalmente, Mercedes y Antonio contraen matrimonio por conveniencia. 
En este sentido, Soledad Acosta desentimentaliza el género novelesco (" ¡Es tan desalentador sentir el corazón vacío, sin emociones ni entusiasmo!" [58]). Deja trazos de su reflexión metadiscursiva ("yo no soy héroe de novela") para inclinarse más por otro tipo de modelo narrativo, digamos más "realista", que le permite explorar el interior de una subjetividad y construir un "cuadro psicológico", distanciándose de las obligadas retóricas fundacionales de las letras patrias, que focalizaban la materia narrativa en torno a la compulsión familiar y a la des-figuración de la mujer en tanto sujeto sexual y racional ${ }^{6}$. El relato de Pedro apenas logra ocupar una tercera parte de la novela, cuando son las cartas y la voz de Dolores las que toman la escena y desplazan el meollo sentimental. Su pacto se inscribe en una estética que, si bien ataca la "lacrimomanía" de los folletines, busca la exposición de otro tipo de pulsiones, que no pasan necesariamente por el idilio y las tramas del corazón:

Tía, esta es nuestra última conversación. Hablemos con toda la cordura y resignación que puede tener un cristiano en su lecho de muerte. No permitamos que nos interrumpan las lágrimas, y no seamos débiles [...]. Cuando lleguemos a la orilla del monte me adelantaré sin decir nada. No pronunciemos la palabra adiós; ambas necesitamos de un valor que nos abandonaría si nos despidiésemos. (74, el énfasis es mío)

Soledad Acosta, al distanciarse del proyecto romántico de las narrativas que prescriben el idilio como única posibilidad para la mujer -distancia medible al pasar del él a un yo ella-, puede romper con la convención omnisciente del narrador masculino y configurar, a partir del modelo autobiográfico, una subjetividad moderna, la de la mujer. De este modo la recupera como un sujeto equidistante tanto de su fetichización, como ángel o como demonio, y explora el "lado oculto del corazón", ese ángulo ciego tanto para la mirada médica como para el letrado.

El realismo o el naturalismo eran estéticas más "viriles", es decir, estéticas de combate, que ofrecían un mejor espacio para examinar sujetos desplazados

$6 \quad$ El proyecto de Soledad Acosta con Dolores era más radicalmente contestatario en cuanto a los patrones narrativos circulantes, si lo comparamos con la novela "fundacional" de su compatriota Jorge Isaacs, María (ambas fueron publicadas en el mismo año, 1867). La crítica ya ha señalado sus parecidos y diferencias: entre Efraín y Pedro, que son médicos y primos; y entre María y Dolores, la enfermedad de las dos protagonistas. Pero la apropiación y el sentido semántico de la enfermedad (lepra y epilepsia) adquirieron significaciones diametralmente opuestas. Mientras que Isaacs refrendaba la ideología patriarcal de los relatos degenerativos, Soledad Acosta ponía en evidencia la clave de sus dispositivos. 
y socialmente problemáticos, como en este caso el ascenso de la mujer intelectual. Al poner en entredicho la naturaleza afectiva diseñada para la mujer ("no permitamos que nos interrumpan las lágrimas"), apropiándose de la facultad racional destinada al hombre ("hablemos con toda cordura"), desestabilizaba los esquemas románticos. Al potenciar la creatividad del logos, de algún modo la escritora no solo se estaba "virilizando" -porque tomaba en sus manos la pluma/ el pene-, sino que también se estaba des-corazonando. Es, por tanto, también un ejercicio de escritura autobiográfica en reverso -no promueve el modelo de esposa ejemplar-, porque desmiente la fragilidad de su género ("y no seamos débiles"), la incapacidad intelectual de la mujer ("cuán indispensable es saber"), la necesidad de protección ("Viviré sola [...] amenacé seriamente que me huiría de la casa y conseguí hacerlo" [69]), y la belleza física como capital ("Su belleza había desaparecido [...] se veía como un espectro entre las sombras", 69). Desde este ángulo, es interesante no dejar pasar otros sentidos posibles en la selección de la lepra como enfermedad: al descarnar el cuerpo de la paciente, va perdiendo su sensibilidad ("los médicos dicen que el lazarino ha perdido el sistema nervioso" [84]), lo que metafóricamente la "des-sensibiliza" para los excesos literarios, es decir, le permite despedirse de la tía sin melodramas ("no pronunciemos la palabra adiós") y abordar ciertos temas sin perder la "cordura":

Acaso me creerás insensible, desnaturalizada, al ver que puedo hablar tranquilamente de la muerte [...]. No sé qué decir: no me comprendo a mí misma y creo que hasta he perdido la facultad de sentir. Nunca lloro: la fuente de las lágrimas se ha secado; no me quejo, ni me conmuevo. (79, el énfasis es mío)

La nueva estética propuesta disocia la facultad de sentir con la fuente de las lágrimas y las quejas, lo que saca a la mujer del callejón de la irracionalidad naturalizada de la ideología patriarcal y la coloca como sujeto pensante ("Mándame algunos libros. Quiero alimentar mi espíritu con bellas ideas" [79]), pero no necesariamente sin sentimientos. Se desafía la supuesta incapacidad de la mujer para poder articularse dentro del lenguaje verbal. La desentimentalización de la mujer, así como abogar por su derecho a profesar las letras, eran vistos como una pérdida de la feminidad. Soledad Acosta arremete contra el deseo masculino de la mujer débil y sin voluntad, oponiendo la construcción de un caso ejemplar de mujer fuerte y resuelta, cuya independencia también significa el desecho de las prótesis masculinas y poder caminar y hablar por sí misma. También, en cierta forma, la misma enfermedad, al inhabilitarla para ser la mujer doméstica deseada por Antonio, contradictoriamente la equipa ("necesitamos de valor") para enfrentar otro modelo de existencia: la fortalece psicológicamente. 
Las narrativas melodramáticas como las médicas habían estandarizado la somatización de los sentidos simbólicos del lenguaje del cuerpo femenino, en el entendido de que la mujer no era capaz de explicarse en el discurso racional de la palabra y, por tanto, solo podía hablar a través de su cuerpo (Beizer; Silva; Vrettos). Necesitaba de interpretación: un ojo que la anatomizara desde la razón clínica. Desde esta lógica, el sujeto médico letrado era indispensable para descifrar el lenguaje "desarticulado" del cuerpo de la mujer, y disponer sus sentidos (los de la lógica patriarcal) dentro del orden del discurso. Recordemos que Pedro como médico presenta el caso de Dolores, evalúa su enfermedad. Sin embargo, no habla por ella...

La atención que recibieron el cuerpo y la conducta de la mujer durante el siglo XIX propició buena parte del desarrollo de las narrativas médicas. El cuerpo de la mujer intrigaba, bien por temor a su sexualidad, bien por temor a su independencia. Auscultar, diagnosticar, anatomizar ese cuerpo eran una manera de vigilarlo, cercarlo y pre-escribirlo dentro de la autoridad de la letra científica, que al paso legitimó representaciones de la mujer basadas en el ojo y el interés del saber patriarcal. De este modo, el sujeto médico habló por ella, y decidió sus patologías, y obviamente, la etiología moral de sus padecimientos. En este sentido es muy significativo cómo operaba el teatro clínico de la Salpêtrière del doctor Charcot, quien mostraba los casos de histéricas, neuróticas y epilépticas efectivamente en un anfiteatro, donde la paciente ocupaba el escenario de "disección", mientras una nutrida concurrencia de médicos observaba el cuerpo convulso de las enfermas. El ojo clínico trataba de leer los síntomas de un striptease de cuerpos que se ofrecían al deseo médico de penetrar los secretos de la enfermedad. O, con más precisión, la mirada médica proyectaba sobre esos cuerpos sus deseos eróticos reprimidos en forma del lenguaje simbólico de las patologías. De este modo, las narrativas médicas fabricaban un saber sobre el cuerpo de la mujer a partir de dispositivos que privilegiaban los mecanismos panópticos del espectáculo y de la mirada vigilante. La voz de la paciente enmudecía, y solo su cuerpo hablaba.

Por ello mismo, Dolores no se deja ver ("no se dejaba ver de nadie, y no permitía que se le acercasen" [68]), porque no desea que su cuerpo sea el libro donde los médicos interpreten el sentido del lenguaje de la mujer. El cuerpo de la diferencia de género no es traducible. No es transparente y, por tanto, la interpretación basada en el sentido de la vista es susceptible de espejismos y distorsiones. Recordemos que Dolores es traductora, no solo ejercitada en trasladar el sentido de las palabras de un idioma a otro (del francés al español), sino también del sentido de ciertos conceptos de una cultura a otra. En última instancia, la traslación 
de un código a otro no es posible sin alterar los sentidos. Desde la perspectiva de los médicos (para Pedro y su padre) la tez de Dolores "no es natural en este clima" (27, el énfasis es mío); leen, al ver la conducta de Dolores -más inclinada a las letras que al matrimonio-, una anormalidad que debe ser patologizada. Soledad Acosta construye con Dolores su caso al quebrar la gramática basada en el mimetismo de la mirada que "mal-interpreta" el sentido de la enfermedad de Dolores. El cuerpo diferente solo puede dif(i)erenciarse si le permiten hablar y precisar sus sentidos, estableciendo, entonces, una voz diferida. Aquí se reprograman los canales de comunicación. La lepra como enfermedad entraña, en este punto, una categoría epistemológica que anula las narrativas médicas basadas en el saber especta-ocular para descifrar al otro sexuado; para instalar otra situación que obliga al sujeto masculino a escuchar -a Pedro solo le queda oír a Dolores en una forzosa situación de escucha-cómplice-, y al sujeto femenino poder traducirse (inscribirse) en la letra hablada o escrita.

En este sentido, Soledad Acosta re-escribe las narrativas médicas a partir de sus presupuestos. Asume la condición de leprosa para la mujer contagiada por las letras, y conspira desde las condiciones de esta enfermedad en contra de las premisas del saber de la autoridad médica. La lepra desintegra la materialidad del cuerpo; luego, hay poco o nada que ver para anatomizar. En cierta oportunidad, Dolores escapa de la mirada del médico y de su tía que van a verla, adentrándose aún más en la selva. Durante la noche se cobija en la choza de una mujer tullida que vive con su hijo retrasado. Esta microcomunidad de seres incompletos y deformes -no en vano son mujeres y niños- que viven marginados refuerza por contigüidad la imagen de la mujer letrada como un individuo mutilado. La tullida es también la otra cara de Dolores.

A despecho de la inevitable desexualización que conlleva ideológicamente esta enfermedad (la lepra), el único cuerpo que resta para el diagnóstico es el cuerpo in-material de la voz, el texto sustitutivo de la carne que se desintegra. También, por consiguiente, se abre el intersticio para la creación de una subjetividad que toma cuerpo en la escritura, con lo cual la representación de la mujer escapa del abanico de cosificaciones (virgen, madre, santa, puta, bruja, demonio, vampiro), para devenir en un sujeto psicologizado. La representación masculina de la in-validez de la mujer letrada queda forzosamente revertida al situar a la mujer como autoridad de su propio discurso.

De este modo, Soledad Acosta, más cercana a las narrativas humanitarias heredadas de la Ilustración, promueve dispositivos que desde la ficción puedan crear una sensibilidad solidaria (Pedro se convierte en un interlocutor fraterno y no paterno de Dolores) con los conflictos y padecimientos de las mujeres que no 
se ajustan al modelo doméstico y a las narrativas de la familia sentimental. Ahora, el sello viril de las letras queda contagiado con los fragmentos de la voz femenina. Después de todo, la feminización de Pedro prepara el escenario para un canon literario tal vez compartido fraternalmente.

\section{Otras metáforas: ¡tuberculosis no!}

La intelectualidad femenina causaba en el XIX profundas inquietudes entre la comunidad de letrados y artistas, que veía amenazada su autoridad con el ascenso de un nuevo sujeto que no solo le podía disputar el terreno de las representaciones simbólicas de la cultura, sino desdibujar la distribución sexuada de los espacios público y privado, además de alterar imprevisiblemente la decisión de los asuntos del Estado (Dijkstra). La posible disminución de este poder (más fantasmagórico que real) activó en el inconsciente de las sensibilidades viriles una misoginia sin precedentes, que se apresuró a elaborar una gama variopinta de estereotipos femeninos, desde imágenes tranquilizantes y dulcificadas hasta representaciones diabólicas y monstruosas de la mujer. Convivieron a lo largo del siglo una oferta riquísima de tipologías, algunas preventivas -como las del dulce ángel del hogar, la madre abnegada cargada de hijos, o la enferma y moribunda-; otras conjuratorias -como la Salomé, la Judith, la Eva, la Medusa, la Vampiresa, o las odaliscas-; y otras en las que la mujer aparecía como pura fuerza física reducida a su masa laboral -lavanderas, costureras, sirvientas, campesinas-. Las primeras reprimían y encorsetaban; las segundas liberaban e hipertrofiaban; y las terceras mutilaban. Todas eran devaluadas. En todo este repertorio de posibilidades, lo que incomodaba era la injerencia de la mujer en las zonas "viriles" de la cultura, el poder de las letras, de las artes y de los negocios: el miedo masculino que despertaba la mujer que leía/escribía -en este renglón no fueron pocos los ejemplos de su representación- y la mujer saludable, fuerte, dueña de finanzas y haciendas. El temor a perder su hegemonía proyectaba esa ansiedad a las representaciones simbólicas, transfiriendo la violencia de su propio despojo al objeto de su castración. Esto podría explicar solo en parte la dificultad para incorporar en el imaginario social del periodo imágenes más normalizadas del "segundo sexo".

En este sentido, una de las estrategias más recurrentes fue invalidar el cuerpo femenino convirtiéndolo en fuente de agentes patógenos. De eso se encargaron tanto las narrativas sentimentales del romanticismo como las médicas del naturalismo. Controladas ambas por compulsiones higienizantes y categorías de pureza, popularizaron el cuerpo degenerado de la mujer, estigmatizado por la culpa de enfermedades venéreas o la debilidad por diferencias sociales y étnicas. $\mathrm{Al}$ respecto, una de las imágenes más emblemáticas de la protagonista romántica 
es la tuberculosa, entre ellas, la más conocida, la Margarita Gautier de La Dama de las Camelias y, posteriormente, la Mimí de la ópera La Bohème.

No ahondaremos en este punto, pero sí recordemos lo esencial: el imaginario misógino de la estética romántica -que no se desgastó hasta 1900- trabajó con ahínco la tuberculosis como enfermedad, que atacaba con preferencia a los seres de vida disipada: a las mujeres que llevaban una vida sexualmente indecorosa (es decir, que eran prostitutas). Al contraer la tisis se establecía una carga moral entre la enfermedad y el exceso sexual; del mismo modo, los hombres contagiados eran artistas que habían perdido la salud por excesos y miserias económicas (Sontag). En cualquiera de los dos casos, la tuberculosis estaba asociada a un desborde de pulsiones (sexuales y etílicas), a pasiones in-disciplinadas de sujetos (masculinos y femeninos), que se ubicaban en las zonas ex-céntricas del cuadro social, que en su mayoría provenían de los sectores menos favorecidos. Por consiguiente, esas metáforas de la enfermedad estaban ligadas a la bohemia, al dandismo letrado y al exceso sexual. Era difícil por tanto para Soledad Acosta encontrar en este repertorio disponible una imagen para la mujer letrada que no estuviera asociada ni a la tuberculosis ni a la sífilis, porque ambas estaban cargadas, específicamente para el caso de la mujer, de un exceso melodramático -de amores, idilios y pasiones- que no se avenía al personaje de Dolores, cuya "anormalidad" debía estar liberada de cualquier connotación culposa. Después de todo, ser letrada no debía ser un pecado, como tampoco estar emparentada a la vida bohemia. Además, una heroína tuberculosa, con sus profundas ojeras y su palidez mortal, revestía, de acuerdo a la moda, mayores atractivos y terminaba por satisfacer el deseo masculino de cumplir con las demandas de una mujer débil, fragilizada por la enfermedad y sin voluntad. Recordemos que en el horizonte literario colombiano Jorge Isaacs, en los mismos años, estaba proponiendo con María (1867) un modelo de protagonista también enferma (de epilepsia), pero ajustado al gusto romántico de la mujer desvalida y sentimental. Al rechazar gran parte de las retóricas en boga, Soledad Acosta descartaba consecuentemente las metáforas de la tuberculosis, y se adelantaba avant la lettre a las narrativas médicas que se desarrollarían hacia finales del siglo.

Sin embargo, la etiología de la lepra estaba desligada de una contextualización sociohistórica (nada tenía que ver con desvíos humanos); su origen se anclaba en una mitología religiosa. Tenía que ver más bien con la ira divina. De algún modo, el leproso transitaba con una doble carga moral: por un lado, expiaba un castigo divino en su cuerpo; pero, por el otro, al tratarse de un castigo divino gozaba de cierta trascendencia. Era a la vez des-graciado: tenía y no la gracia de Dios. Dolores tiene el don divino de la palabra; pero, al ser mujer, el don divino 
del verbo (que pertenece por ley al padre) ha recaído en manos equivocadas; se ha desviado de su curso normal (patrilineal); por ello se ha (des)graciado: puede escribir ("unos preciosos versos, que mostraban un profundo sentimiento poético"). Pero como la tradición ha desviado su curso, la transgresión de esta gramática debía ser expiada bajo la forma de su máxima monstruosidad (la lepra) que, al mismo tiempo, la confinaba al mayor aislamiento.

Abrazar la (des)gracia de la escritura en una sociedad donde las letras estaban gobernadas por manos masculinas equivalía a violar las normas sociales; y era también arriesgarse a llevar el peso de la máxima culpa, de la más abominable de las metáforas: la que convierte a la mujer letrada en un monstruo de rostro irrepresentable, porque en su desfiguración ha tergiversado el sentido del cuerpo biológico de la reproducción en cuerpo intelectual de la palabra.

\section{Obras citadas}

Abel, Elisabeth, ed. Writing and Sexual Difference. Chicago:

The University of Chicago Press, 1982.

Acosta de Samper, Soledad. La mujer en la sociedad moderna.

París: Casa Editorial Garnier Hermanos, 1895.

Una nueva lectura. Introducción de Montserrat Ordóñez.

Bogotá: Fondo Cultural Cafetero, 1988.

Anderson, Linda. Autobiography. Nueva York: Routledge, 2001.

Armstrong, Nancy. Deseo y ficción doméstica. 1987. Madrid: Cátedra, 1991.

Bailin, Miriam. The Sickroom in the Victorian Fiction. The Art of

Being Ill. Cambridge: Cambridge University Press, 1994.

Beizer,Janet. Ventriloquized Bodies: The Narrative Uses of Hysteria in France

(1850-1900). Ithaca-Londres: Cornell University Press, 1993.

Bejar, Helena. La cultura del yo. Madrid: Alianza, 1993.

Butler,Judith. Gender Trouble: Feminism and the Subversion

of Identity. Nueva York: Routledge, 1990.

Derrida, Jacques. La escritura y la diferencia. 1968. Barcelona: Anthropos, 1989. "La différence". 1968. Márgenes de la filosofía. Madrid: Cátedra, 1994. 35-52. El monolingüismo del otro o la prótesis de origen. 1996. Buenos Aires: Manantial, 1997.

Dijkstra, Bram. Idols of Perversity. Fantasies of Feminine Evil in Fin-desiécle Culture. 1986. Oxford: Oxford University Press, 1988.

Douglas, Ann. Feminization of American Culture. 1977. Nueva York: Anchor Books, 1988. Franco, Jean. Las conspiradoras. La representación de la mujer en México. 1989.

México: Colegio de México y Fondo de Cultura Económica, 1994. 
García-Pinto, Magdalena. "Enfermedad y ruina en la novela sentimental hispanoamericana: Dolores de Soledad Acosta de Samper". Revista de Estudios Colombianos 18 (1998): 19-26.

Gilman, Sander L. Difference and Pathology. Stereotypes of Sexuality, Race and Madness. 1985. Ithaca: Cornell University Press, 1994.

Gonzales Ascorra, Martha. La evolución de la conciencia femenina a través de la novelas de Gertrudis Gómez de Avellaneda, Soledad Acosta de Samper y Mercedes Cabello de Carbonera. Nueva York: Peter Lang Publishing, 1997.

Gubar, Susan y Sandra Gilbert. The Madwoman in the Attic. 1979. New Haven: Yale University Press, 1984.

Hallstead, Susan. “ ¿Una nación enfermiza? Enfermedad grotesca y escritura femenina en Dolores de Soledad Acosta de Samper". UPenn Working Papers in Romance Languages 4 (1999-2000): 69-80.

Kahane, Claire. Passions of the Voice. Hysteria, Narrative, and the Figure of the Speaking Woman, 1850-1915. Baltimore: The Johns Hopkins University Press, 1995.

López Sánchez, Olivia. Enfermas, mentirosas y temperamentales. México: Plaza y Valdés, 1998.

McMillen Conger, Syndy. Sensibility in Transformation. LondresToronto: Associated University Press, 1990.

Nouzeilles, Gabriela. Ficciones somáticas. Naturalismo, nacionalismo y políticas médicas del cuerpo (Argentina 1880-1910). Rosario, Argentina: Beatriz Viterbo, 2000.

Ordóñez, Montserrat. "Soledad Acosta de Samper: una nueva lectura". Nuevo Texto Crítico II.4 (1989): 49-55.

Price Herndl, Diane. Invalid Women. Figuring Feminine Illness in American Fiction and Culture, 1840-1940. Chapel Hill: The University of North Carolina Press, 1993.

Rodríguez-Arenas, Flor. "Soledad Acosta de Samper: pionera de la profesionalización en la escritura femenina colombiana". Eds. María Mercedes Jaramillo, Ángela Robledo y Flor Rodríguez-Arenas. ¿ Y las mujeres? Ensayos sobre literatura colombiana. Medellín: Editorial de la Universidad de Antioquia, 1991. 133-175.

Russ, Joanna. How to Supress Women's Writing. Austin: University of Texas Press, 1983. Russo, Mary. The Female Grotesque. Risk, Excess and Modernity. Nueva York: Routledge, 1994.

Scarry, Elaine. The Body in Pain. Nueva York: Oxford University Press, 1985.

Scott, Nina M. "He Says, She Writes: Narrative Collaboration in Soledad Acosta de Samper's Dolores". Ed. Joanna Courteau. Mujer, sexo y poder en la literatura femenina iberoamericana del s. XIX. Monografías 4. Valladolid: Anejos, 1999. 83-89.

Scott, Nina M. "Leprosy, the Female Body and Stages of Dying in Soledad Acosta de Samper's 
Dolores". Ponencia presentada en LASA, Miami, 2000. Texto mimeografiado.

Showalter, Elaine. The Female Malady. Nueva York: Pantheon Books, 1985.

Silva Beauregard, Paulette. De médicos, idilios y otras historias. Relatos sentimentales y diagnósticos de fin de siglo (1880-1910). Bogotá: Editorial Universidad de Antioquia y Convenio Andrés Bello, 2000.

Skinner, Lee. "Gender and History in Nineteenth-Century Latin America: The Didactic Discourses of Soledad Acosta de Samper". INTI 49-50 (1999): 71-90.

Sontag, Susan. La enfermedad y sus metáforas. 1977. Barcelona: Muchnik, 1985.

Stallybrass, Peter y Allon White. The Politics \& Poetics of

Transgression. Cornell: Cornell University Press, 1986.

Vallejo, Catharina. "Dichotomy and Dialectic: Soledad Acosta de Samper's. Una

Holandesa en América and the Canon". Monographic Review / Revista Monográfica 13 (1998): 273-285.

Vicinus, Martha, ed. Suffer and Be Ill. Women in the Victorian Age. BloomingtonLondres: Indiana University Press, 1972.

Vrettos, Athena. Somatics Fictions. Imagining Illnes in Victorian Culture. Stanford:

Stanford University Press, 1995. 